\title{
OCORRÊNCIA DE Bacillus coagulans E CONTAGEM BACTERIANA TOTAL EM TOMATES E SEUS PRODUTOS NO ESTADO DE SÃO PAULO
}

SANDRA M. FERRAZ DE ARRUDA SPOSITO

Orientador: Prof. Dr. HOMERO FONSECA

Dissertação apresentada à Escola Superior de Agricultura "Luiz de Queiroz", da Universidade de São Paulo, para obtenção do título de Mestre em Agronomia. Área de concentração: Microbiologia Agrícola.

PIRACICA B A

Estádo de São Paulo - Brasil Junho de 1984 
.ii.

\begin{abstract}
A meus pais e irmãos
que muito contribuiram

para a minha formação,
\end{abstract}

minha gratidão.

Ao meu esposo, Reginaldo

$e$ meus filhos,

Ricardo, Eduardo e Juliana,

DEDICO 
A autora expressa seus agradecimentos:

- Ao Prof. Dr. Homero Fonseca pela amizade, es tímulo e segura orientação durante a realização deste trabaLho;

- A Fundação de Amparo à Pesquisa do Estado de São Paulo, pelo apoio financeiro, tornando possivel a realiza ção desta pesquisa;

- Ao Prof. Dr. Jose Santo Goldoni, da Faculdade de Ciências Agronônicas do Campus de Botucatu, pela sua orientação, receptividade e ensinamentos recebidos;

- Ao Prof. Antonio Joaguim de oliveira pelo acolhimento junto ao laboratório do Departamento de Tecnologia Rural e apoio;

- Ao Prof. Alcides Martinelli Filho pelas sugestões por ocasião da redação da tese;

- Aos professores do curso de Pós-Graduação em Microbiologia Agrícola da Escola Superior de Agricultura "Luiz de Queiroz", USP, pelos vajiosos ensinamentos recebidos;

- Aos funcionários do Departamento de Tecnologia Rural da Escola Superior de Agricultura "Luiz de Queiroz" 
iv.

pela amizade e colaboração prestada;

- A Costa Pinto Industrial de Alimentos Ltda., pela permissão na coleta das amostras de tomate.

$E$ a todos que direta ou indiretamente contribuiram para a realização deste trabalho. 


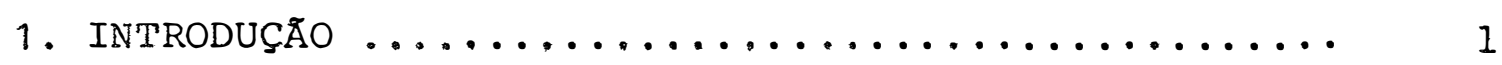

2. REVisão de Literatura $\ldots \ldots \ldots \ldots \ldots \ldots \ldots \ldots \ldots \ldots \ldots$

2.1. Introdução $\ldots \ldots \ldots \ldots \ldots \ldots \ldots \ldots \ldots \ldots \ldots$

2.2, Caracteristicas de Bacillus coagulans ...... 7

2.3. Distribuição de esporos da bactéria "flat-

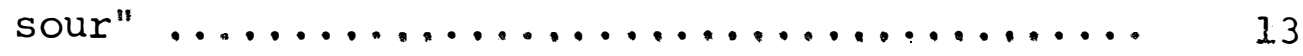

2.3.1. Solo e água $\ldots \ldots \ldots \ldots \ldots \ldots \ldots \ldots \ldots 13$

2.3.2. Leite $\ldots \ldots \ldots \ldots \ldots \ldots \ldots \ldots \ldots \ldots \ldots$

2.3.3. Açúcar e amido $\ldots \ldots \ldots \ldots \ldots \ldots \ldots . . \ldots$

2.3 .4 , Ingredientes $\ldots \ldots \ldots \ldots \ldots \ldots \ldots . \ldots \ldots$

2.3,5. Tomate e seus produtos $\ldots \ldots \ldots \ldots \ldots \quad 17$

2.4. Controle ........................ 18

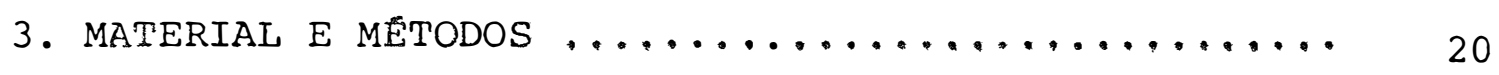

3.1. Material ........................ 20

3.2. Meios de cultura $\ldots \ldots \ldots \ldots \ldots \ldots \ldots \ldots . \ldots . \ldots . \ldots 20$

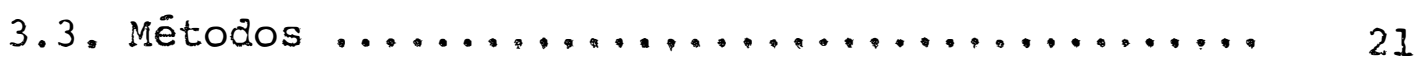

$3,3.1$. Coleta das amostras $\ldots \ldots \ldots \ldots \ldots \ldots .21$

3.3.2. Preparo das amostras ............ 23

3.3.3. Contagem de Bacillus coagulans em toma te e produtos derivados ........... 24

$3 \cdot 3 \cdot 3 \cdot 1$. Contagem total .......... 25

3.3.3.2. Contagem de esporos ....... 25

3,3,4. Contagem de microrganismos em tomate e seus produtos $\ldots \ldots \ldots \ldots \ldots \ldots \ldots \ldots$ 


\section{página}

3.3.4.1. Contagem total .......... 27

3.3.4.2. Contagem de esporos ....... 27

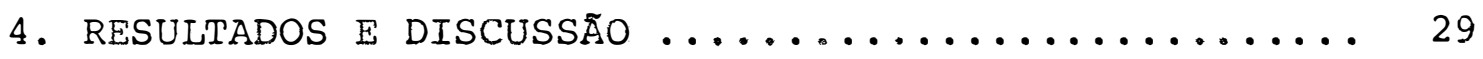

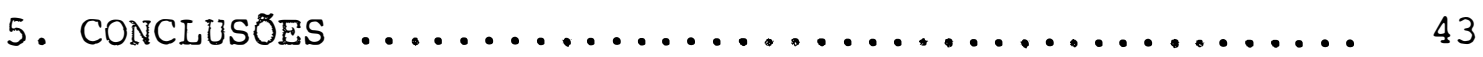

6. IITERATURA CITADA $\ldots \ldots \ldots \ldots \ldots \ldots \ldots \ldots \ldots \ldots \ldots \ldots$ 


\title{
OCORRENCIA DE Bacillus coagulans E CONTAGEM BACTERIANA TOTAL EM TOMATES E SEUS PRODUTOS NO ESTADO DE SAOO PAULOO
}

\begin{abstract}
Autora: Sandra Maria Ferraz de Arruda Spesito Orientador: Prof. Dr. Homero Fonseca
\end{abstract}

RESUMO

O presente estudo teve como objetivo verificar a incidência de Bacillus coagulans e a contaminação bacteriana total em tomate e seus produtos.

o material utilizado na anälise constituiumse de 120 amostras de tomate bruto e lavado, suco antes da concentração, polpa concentrada e extrato coletados semanalmente em uma indústria alimentícia no município de Botucatu (SP).

Para a quantificação, foi utilizada a técnica de contagem em placas (pour plate) em GTY, com incubação a $37^{\circ} \mathrm{C}$ durante 48 horas, para a contagem total de microrganis mos e em NCA, com incubação a $45^{\circ} \mathrm{C}$, durante 48 horas, para a contagem de Bacillus coagulans.

Os resultados revelaram indices variāveis de contaminação total de microrganismos nas amostras analisadas, sendo mais intensa na matêria-prima bruta, que apresentou tam 
.viii.

bëm, maior incidência de Bacillus coagulans, tanto em contagem total como em contagem de esporos.

De um modo geral, o nümero de microrganismos presente nas amostras analisadas foi grande, porêm, a incidên cia de Bacillus coagulans mostrou ser baixa no Estado de são Paulo.

Não houve predominância de incidência de $B a-$ cillus coagulans em qualquer das regiões tomateiras do Estado de São Paulo analisadas. 
OCCURRENCE OF Bacillus coagulans AND TOTAL BACTERIAL COUNT IN TOMATOES AND THEIR BY-PRODUCTS IN THE STATE OF SAO PAULO

Author: SANDRA MARIA FERRAS DE ARRUDA SPOSITO Adyiser: PROF. DR. HOMERO FONSECA

SUMMARY

In the present work it was studied the occurrence of Bacillus coagulans and total bacterial count in tomatoes and their by-products, in the state of são Paulo.

on hundred and twenty samples of raw and washed tomatoes, pre-heated juice (prior to concentration) and concentrated pulp or tomato paste were collected weekly in a food processing plant located at Botucatu (SP).

Bacillus coagulans and total bacterial counts were made on plates in GrY incubated at $37^{\circ} \mathrm{C}$ for 48 hours and also in NCA incubated at $45^{\circ} \mathrm{C}$ for 48 hours.

The results showed a varied contamination of microorganisms in the samples, being more intense in raw tomatoes either for total counts or for Bacillus coagulans. 
was high but the incidence of Bacillus coagulans showed to be low in the state of são paulo.

The incidence of Bacillus coagulans was not predominant in any region of the state of são Paulo. 
1. INTRODUÇÃO

O tomate é originário do Equador e Norte do Chile (JENKINS, 1948) e, provavelmente, também das Ilhas Galá pagos (RICK, 1967). E uma hortaliça cultivada em todo o mundo sendo, portanto, de grande importância, não só em termos de produção, como também em valor econômico, em virtude de ser, seguramente, a cultura mais industrializada.

O tomate pode, através de um processamento ade quado, dar origem a inưmeros produtos, alguns deles; de eleva do consuno no Brasil. Assim, pode--se obter, do tomate inteiro, o tomate pelado e do quebrado, em diversos graus de inten sidade, suco, polpa concentrada, purê, catchup, extratos, molhos culinários e inclusive tomate em pó.

Os produtos enlatados resultantes da industria lização do tomate apresentam as mais variadas aplicações, des 
de que possuam bom sabor, aroma, aspecto e valor nutritivo para competir com o produto fresco encontrado o ano toảo.

A industrialização do tomate no Brasil iniciour.se durante a Segunda Gerra Mundial. Até então, a maior parte do tomate industrializado era importado da Argentina ou Itália, com alguma produção de origem caseira.

No Brasil, houve um significativo aumento na produção de tomate a partir de 1972. As indústrias existentes aumentaram sua capacidade e outras novas foram instaladas em diversas regiōes. Os maiores produtores são os Estados ảe Säo Paulo, Paraná, Minas Gerais, Pernambuco, Rio de Janeiro e Rìo Grande do Sul.

De acordo com O IBGE (Instituto Brasileiro de Geografia e Estatistica - 1982) a produção brasileira de toma te atingiu 1.739.527 toneladas em 1982, O Estado de São Pau1o, com produção de 826.000 toneladas nesse mesmo ano, foi o responsável por 918 da capacidade de industrialização do tomate (MINAMI, $\$ 980)$.

A cultura do tomate rasteiro no Estado de são paulo é destinada, em sua maioria, para a industrialização. As äreas de maior produção são as de Presidente Prudente, Ara çatuba, São José do Rio Preto e outras (TESSARIOLI, 1980).

A deterioração do tomate "in natura" pode ser devida a fatores físicos, ação de seus pröprios ênzimos, ação 
de microrganismos ou ação combinada desses fatores.

Os danos mecânicos, resultantes de cortes, machucaduras e manuseio inadequado, podem predispor a entrada e posterior desenvolvimento de microrganismos.

O manuseio impróprio e as condições inadequadas durante a colheita, transporte, armazenamento e venda do produto podem favorecer a deterioração.

O controle microbiológico do tomate "in natur ra" e de seus produtos derivados é de importância devido ao grande consumo dos mesmos.

O tomate pode ter uma flora microbiana variável, dependendo da condição fisica do fruto durante a colhei ta e transporte, da quantidade e tipo de solo aderente ao mes mo e do seu tempo de armazenamento.

A alteração microbiológica dos produtos de tomate industrializados está geralmente associada ao desenvolvi mento de grupos especificos de microrganismos, tais como: Lac tobacillus, Bacillus, leveduras e certos butíricos anaerōbi-.. cos (TANNER, 1950; JONES e FERGUSON, 1961), além de fungos.

Entre as bactêrias esporogênicas aeróbicas ou anaeróbicas facultativas, que resistem mais ao calor e causam deterioração nestes produtos, a espécie mais importante é Bacillus coagulans. A sobrevivência desta bactēria em produtos 
enlatados pode causar um sério problema de deterioração bioló gica, onde as extremidades das latas permanecem planas durante o "souring" ou acidificação, por fermentação de carboidratos, principalmente, açūcares, com produção de ácidos, porém, sem gases. Como a lata apresenta aparência normal, sem qualquer estufamento, o desenvolvimento desta bactéria não é facilmente perceptivel, sendo detectado, inicialmente, pelo sabor, $\mathrm{pH}$ e odor do produto, seguido por testes diagnósticos com inclusão de exames microscópicos e de culturas.

$\mathrm{Na}$ indústria de enlatamento, a carga e o tipo de microrganismo presente no alimento determinam o tempo e a temperatura necessários para a esterilização comercial do mesmo, especialmente, se a contaminação introduz organismos detexioradores resistentes ao calor.

Embora o tomate "in natura" e seus produtos se jam ácidos, estão sujeitos à deterioração, se não apropriadamente manipulados e processados, pelas linhagens termo-resistentes de Bacillus coagulans, que sobrevivem ao processo térmico convencional.

o presente trabalho teve como objetivo verificar a incidência de Bacillus cogulans e a contaminação bacte riana total em tomate na indústria, antes, durante e após o processamento, para que se pudesse aquilatar se as mesmas poderiam se constituir em problema para a conservação dos produ tos de tomate. 


\section{REVISÃO DE LITERATURA}

\subsection{Introduçăo}

Durante um estudo sobre a coagulação de leite desiaratado, HAMMER (1915), na Estação Experimental Agrícola de Iowa, isolou, pela primeira vez, um organismo que ele deno minou Bacillus coagulans porque causou coagulação de leite en latado, sem produção de gás. Esse microrganismo produziu cer ca de 1\% de äcido nas latas do leite enlatado.

A relação entre Bacillus coagulans e deterioração "flat-sour" não foi estabelecida senão vários anos apōs o trabalho original de HAMMER (1915).

$$
\text { CORDES (1928) relatou a ação de }
$$

bactērias

"flat-sour" na coagulação de leite desidratado. Ele atribuiu a deterioração ocorrida, apôs tratamento tẻrmico, a Bacillus coagulans. 
BERRY (1933), investigando o primeiro relato do surto de deterioração em suco de tomate, achou ser o organismo responsável uma bactéria esporogênica encontrada no so1o. Baseado em sua natureza termofillica, sua tolerância ao calor e sua habilidade em crescer em produtos ácidos, aquele autor denominou este organismo de Bacillus thermoacidurans.

Posteriormente, BECKER e PEDERSON (1950) fizeram um cuidadoso estudo das duas espécies de Bacillus e concluiram que não havia justificativa em considerar Bacillus thermacidurans como uma espécie distinta de Bacillus coagulans, sendo que este ủltimo none tinha prioridade.

Donk, citado por F'IELDS (1970) identificou B B cillus stearothermophylus como o tipico deteriorador de vegetais com baixa acidez e Bacillus coagulans como o responsável pela deterioração "flat--sour" em produtos de tomate e leite.

A deterioração do suco de tomate enlatado comercialmente foi relatada pela primeira vez em 1931, segundo TROY e SCHENCK (1960). Desde esta data, surtos deste tipo de deterioração têm ocorrido quase anualmente, muitas vezes, alcançando sérias proporções e causando severos prejuizos econô micos para as fábricas de conservas, nos Estados Unidos.

Até hoje, não existem referências indicando que Bacillus coagulans seja de alguma maneira patogênico ou tóxico, porém, deteriora o produto em que se instala. 
2.2. Caracteristicas de Bacillus coagulans

São bastonetes móveis, apresentando muitos fla gelos por célula. A reação de Gram é usualmente positiva (SPECK, 1976). Em meio NCA, apōs incubação a $37^{\circ} \mathrm{C}$ durante 48 horas, formam típicas colônias amarelas circulares e trans lūcidas no meio de cultura de cor violeta.

BECKER e PEDERSON (1950) reportaram que Bacillus coagulans não é obrigatoriamente termofílico, pois, é capaz de crescer a baixas temperaturas, como $18^{\circ} \mathrm{C}$. Esse micror ganismo cresce bem a temperaturas de $40^{\circ} \mathrm{C}$ a $60^{\circ} \mathrm{C}$ e sua temperatura ótima de crescimento varia de $45^{\circ} \mathrm{C}$ a $55^{\circ} \mathrm{C}$. A temperatura máxima para crescimento varia para diferentes linhagens. Virtualmente, todas as linhagens podem crescer a $60^{\circ} \mathrm{C}$, porém, algumas crescem pobremente a $55^{\circ} \mathrm{C}$ ou a temperaturas mais altas. Não há crescimento típico a $65^{\circ} \mathrm{C}$, embora, crescimento a temperaturas de $63^{\circ} \mathrm{C}$ a $65^{\circ} \mathrm{C}$ tenha sido observado. 0 crescimento a temperatura ambiente é extremamente lento, muito lento a $25^{\circ} \mathrm{C}$ e bom a $30^{\circ} \mathrm{C}$. A temperatura mais baixa na qual pode ocorrex crescimento apreciāvel está entre $25^{\circ} \mathrm{C}$ a $30^{\circ} \mathrm{C}$.

GORDON e SMITH (1949) relataram que 53, de 73 culturas estudadas, cresceram a $28^{\circ} \mathrm{C} ; 73$ a $33^{\circ} \mathrm{C}, 37^{\circ} \mathrm{C}$ e $45^{\circ} \mathrm{C}$; 72 a $50^{\circ} \mathrm{C} ; 66$ a $55^{\circ} \mathrm{C}, 23$ a $60^{\circ} \mathrm{C}$, e nenhuma a $65^{\circ} \mathrm{C}$.

Os esporos de Bacillus coagulans apresentam baixa resistência ao calor quando comparados com esporos de 
termófilos obrigatórios. SOGNEFEST e JACKSON (1947) afirmaram que a maioria das linhagens pode ser destruída em 0,7 minutos a $121^{\circ} \mathrm{C}$. Atualmente, sabe-se que para um valor $\mathrm{D}_{212}=$ $=0,526$ minutos, a indústria usa um valor $\mathrm{F}_{212} 27=$ minutos, que é mais que o necessário para atingir uma esterilização comercial. Mesmo assim, ainda há possibilidade de uma eventual de terioração.

BERRY (1933) indicou que a temperatura de $37^{\circ} \mathrm{C}$ parece ser ótima para a produção de "fllavor" desagradável. A resistência térmica de esporos de Bacillus coagulans é maior em leite desidratado do que em suco de tomate. Esta diferença em resistência ao calor de produtos diversos deve ser mais aparente do que real, porque a influência do pH, lipídios, proteínas e outros constituintes alimentares não tem sido evi denciada. Entretanto, deve-se reconhecer que a resistência térmica dos esporos deste microrganismo pode variar muito com a idade, condições ambientais e linhagens individuais da bactéria.

Bacillus coagulans produz ācido, mas não gâs, com glicose, sob condições aeróbicas, quando peptona é usada como fonte de nitrogênio (BREED et alii, 1929). Outros autores relataram, entretanto, que sob condições aeróbicas, glicose ë convertida a dióxido de carbono, ácido acético e ácido lātico e que, sob condições anaeróbicas, não há produção de gâs, sendo o ācido lātico, o principal produto. 
RICE e PEDERSON (1954) mostraxam que o pH é um Eator significativo na habilidade de germinação de esporos e crescimento de Bacillus coagulans, em produtos de tomate. Es tudando o efeito da concentração de esporos no crescimento de Bacillus coagulans, estes autores verificaram que a quantidade de äcido, que podia ser tolexada por este microrganismo, va riou com a linhagem usada. Paxa uma baixa concentração de es poros (20 ou menos por ml de inóculo), somente 2 , das 20 culturas usadas, Eoram capazes de crescer a pH 4,3I ou mais baixo. Utilizando outras Iinhagens de esporos de Bacillus coagu lans, estes autores verificaram que milhões de esporos causaram deterioxação em 25 a $33 \%$ das amostras de suco de tomate com pH 4,18, mas, a deterioração não foi observada a pH 4, I ou mais baixo.

Bacillus coagulans cresce bem em meio artificial com valores de $\mathrm{pH}$ entre 5,0 e 7,0. PEDERSON e BECKER (1949) mostraram que muitas culturas, em sua forma vegetativa, podem crescex a valores tão baixos com pH 4,02. Em meio artificial, os esporos resistentes ao calor foram "incapazes de germinar e crescer em pH abaixo de 5,0. Usando suco de to mate com värios valores de $\mathrm{pH}$, estes pesquisadores mostraram que células vegetativas de mais de um terço de 22 Iinhagens de Bachleus coagulans cresceram e produziram um "flat-sour" tipico no suco com um valor de $\mathrm{pH}$ de 4,21 ou mais baixo. Es poros das mesmas 22 Iinhagens näo se desenvolveram no suco con pH inicial mais baixo que $4 ; 32$. 
DESROSIER e HEILIGMAN (1956) verificaram que esporos de Bacillus coagulans foram capazes de germinar e crescer em suco de tomate, quando inoculados imediatamente após tratamento térmico, ou se o pH do suco fosse aumentado. Eles também constataram que esporos de Bacillus coagulans cau saram deterioração em suco neutralizado com fosfato de potássio e ajustado ao seu phi original.

Bacillus coagulans é um dos organismos responsáveis pela deterioração "flat.-sour" em alimentos, especial mente, em alimentos ácidos $(\mathrm{pH} 3,7$ a 4,5). Entretanto, embora esta bactéria possa, eventualmente, causar deterioração em alimentos pouco ácidos, isto é muito raro ảevido a baixa resistência ao calor de seus esporos ao severo processo térmico dado a este tipo de alimento.

O "flavor" do suco de tomate deteriorado por esta bactêria tem sido descrito como "ácido", "rançoso", "fenólico", "medicinal" ou "amargo" e, geralmente, acompanhado por uma redução de 0,3 a 0,5 no pH (STERN et alii, 1942). O sabor desagradável pode, algumas vezes, ser detectado antes que qualquer mudança no $\mathrm{pH}$ seja evidenciada, e se desenvolver mais rapidamente em torno de $37^{\circ} \mathrm{C}$.

Quando suco ảe tomate enlatado começou a ser produzido, o pH baixo e o enchimento da lata a quente la temperatura de aproximadamente $100^{\circ} \mathrm{C}$ ) foram considerados suficientes para produzir um produto comercialmente estéril. Os 
esporos de Bacillus coagulans, entretanto, podem sobreviver a este tratamento tërmico e causar deterioração. A acidificação do suco de tomate para pH 4,1 parece adequada para contro lar crescimento na maioria dos casos. A baixa concentração de esporos e um pH de 4,3 em suco de tomate inibirão o cresci mento da maioria das linhagens de Bacillus coagulans. A prē-esterilização por processo HTST lalta temperatura-curto tempo) é usada para controlar este tipo de determinação (DEFIGUEIREDO e SPLITTSTOESSER, 1976) •

E um fato aceitável que o pH é um fator predominante no desenvolvimento desta bactéria em suco de tomate. A faixa de pH normal de tal suco, de acordo com o "Canned Food Reference Manual" (1949), è de 3,8-4,5, em média, 4,2.

JONES e FERGSUON (1961), estudando tomates aspergidos com uma suspensão do Bacillus coagulans, em vários estágios do perído de armazenamento, mostraram um aumento marcante na taxa de crescimento do organismo teste, coincidin do com a mudança no pH. Este aumento na taxa de crescimento ocorreu quando o pH alcançou 4,30 e continuou até o aparecimento de excessiva contaminação por fungos. Estas descobertas sugerem que tomates armazenados após a colheita, particularmente a temperaturas relativamente altas, deve ser um fator predominante no desenvolvimento de deterioração "flat-sour". 
Uma vez que a acidez desempenha um papel impor tante no crescimento de Bacillus coagulans e no desenvolvimen to da deterioração "flat-sour", JONES e FERGUSON (1961) estudaram a influência do $\mathrm{pH}$ de tomates, recentemente colhidos e de tomates armazenados por um período comparável àquele em que os tomates deveriam ser mantidos na fábrica. Dados sobre o $\mathrm{pH}$ de tomates durante 5 anos mostraram amplas variações em tomates frescos, dia após dia, durante o período de colheita. Houve também uma indicação que os tomates tornaram-se menos ácidos com o tempo.

Outros estudos de JONES e FERGUSON (1961) sobre o efeito do armazenamento de tomares antes do processamen to mostraram que o pH médio aumentou de 4,25 para 4,77 durante 11 dias; a faixa de $\mathrm{pH}$ foi de 4,19-4,32 para 4,60-4,95. O pH médio aumentou de 4,41 para 4,77 do 69 para 118 dia. Estes valores de $\mathrm{pH}$ permitiram o rápido crescimento de Bacillus coagulans, com resultante deterioração "flat-sour". Durante este perído $\circ \mathrm{pH}$ de alguns tomates alcançou um valor tão alto quanto 5,0 .

YORK et alii (1974) mostraram a influência da concentração hidrogênio-iônica na germinação de esporos e crescimento de Bacillus coagulans em suco de tomate, após aquecimento a $90^{\circ} \mathrm{C}$ durante 30 minutos. A pH 4,81, a germinação e o crescimento foram definidos. Crescimento a outros ní 
veis de $\mathrm{pH}$ foi questionado, mas, o exame microscópico confirmou crescimento e germinação de esporos em pH 4,81, 4,56 e 4,45. Para valores de $\mathrm{pH} 4,31$ ou mais baixo, somente esporos foram observados.

Como vimos, a presença de esporos de Bacillus coagulans é de grande importância em produtos enlatados com $\mathrm{pH} 4,1$ a 5,0, podendo induzir uma grave consequência econômica para a indūstria, pois, evidenciando-se a deterioração todo o lote deve ser destruído.

2.3. Distribuição de esporos da bactēria "flat-sour"

$$
\text { 2.3.1. Solo e ägua }
$$

MARSH E IARSEN (1953) estudaram isolados de bactérias das fontes quentes do Yellowstone National Park. Algumas cepas tinham caracteristicas de ambos os Bacillus: Ba cillus coagulans e Bacillus stearothermophylus.

Estudos de JONES e FERGUSON (1961), para deter minar a incidência de bactérias "fllat-sour" em tomates de diferentes āreas no Canadá, mostraram que este microrganismo es tava presente em todas as äreas. De 268 amostras de àgua usa das na lavagem de tomates, 214 (80\%) mostraram contagem de 
100 esporos de $B$. coagulans, ou menos, por ml de água. Somen te 12 amostras $(4,5 \%)$ mostraram contagem de esporos acima de 500 por ml de água. Estes resultados sugerem que a concentra ção de esporos desta bactéria na ãgua de lavagem dos tomates da fábrica não foi muito grande durante a ocasião em que o es tudo foi realizado.

Desde que o "habitat" natural de Bacillus coagulans é o solo, compreende-se que o organismo seja carregado para a fábrica no solo aderido aos tomates.

Em um estudo com 41 amostras de solo das Ilhas Hawaianas, FIELDS (1968) verificou que todas as amostras analisadas continham bactērias esporogênicas, aeróbicas e termofillicas, embora o número de esporos encontrado tenha sido pequeno (geralmente menos que 100 esporos por grama).

\subsubsection{Açūcar e amido}

Em 1930, as discussões estavam centralizadas no fato do açúcar estar envolvido na deterioração de alimentos enlatados. INGERSOLL (1930) afirmou que o açūcar não era responsável pela introdução de bactérias termofílicas nos prọ 
cessos de enlatamento, sugerindo que a resposta provável e es te problema era a falta de saneamento em tais processos.

CAMERON E BIGELOW (1931) estudaram bactērias termofílicas em açūcar e verificaram que o grupo "flat-sour" foi o mais frequentemente encontrado e que os esporos do "flat-sour" estavam presentes em todas as amostras de açūcar de cana analisadas.

O amido, assim como o açücar, pode ser uma fon te de esporos de bactérias "flat-sour" em alimentos enlatados.

CLARK e TANNER (1937) verificaram que esporos do "flat-sour" foram os tipos predominantes em açúcar e amido. Em açúcar comercial, 72 amostras continham 0-75 esporos de bactérias "flat-sour", 13 amostras continham 75-150 esporos, e 6 amostras continham mais que 150 esporos por 10 gramas de açücar. Em 20 amostras de amido, o conteúdo de esporos "flat-sour" foi $0-324$ esporos por 10 gramas de amido, com uma mëdia de 139 esporos por 10 gramas. 
2.3.3. Ingredientes

RICHMOND e FIELDS (1966) fizeram um estudo de vários ingredientes alimentares com a finalidade de determinar a distribuição de bactérias esporogênicas, aeróbicas e termofilicas. Alguns dos ingredientes testados foram: açücar mascavo, granulado e comum, amido de milho, farinha de aveia, amido de batata, especiarias, ervilha, cacau, gelatina e sopa desidratada.

A espécie de microrganismo mais encontrada foi Bacillus coagulans, estando presente em 14 dos 18 ingredientes testados.

\section{3 .4 . Tomate e seus produtos}

Bacillus coagulans tem sido isolado de tomate e seus produtos como: suco, purê, sopa, molhos, catchup etc. (SPECK, 1976).

HUSSEIN et alii (1979) fizeram um estudo para determinar o grau de contaminação bacteriolögica na linha de processamento de tomate do Egito. Eles verificaram a presença de Bacillus coagulans entre outras espécies ce Bacillus. 
2.4. Controle

O solo é a fonte de Bacillus cuagulans nos equipamentos de processamento. DOYLE et alii (1958), em um estudo sobre sanificação das instalações de enlatamento, encontraram que o solo nos campos de tomate continha muitos esporos termofilicos. Estes pesquisadores mostraram que havia uma relação bem definida entre a concentração de particulas de solo (em ppm) e o número de esporos "flat-sour" nos tanques de água onde os tomates permaneciam de molho. E importante, portanto, que uma fonte de ảgua potável seja disponivel para a lavagem dos tomates, $\epsilon$ gue os tanques e condutores de ägua tenham um suprimento adequado, adicionado a todo momento, para manter o número de esporos "flat-sour" tão baixo quanto possivel.

$$
\text { YORK et alii (1962) e O'BRIEN et alii (1963) }
$$

constataram que o aumento em nümero de bactérias do ácido lático e fragmentos de fungo em tomates, após 24 horas de armazenagem, foi relacionado não somente à porcentagem de frutos partidos, mas também, a populações microbiológicas iniciais. Esta relação foi enfatizada por avaliações de tomates armazenados por 48 horas (O'BRIEN et alii, 1963).

O nûmero de microrganismos pode ser reduzido a travếs de lavagem de tomates antes do transporte e armazenagem (YORK et alii, 1962; O'BRIEN et alii, 1963). A lavagem apenas com âgua, entretanto, não diminuiu a taxa de crescimen 
to bacteriano durante armazenagem e forneceu um meio que fací litou o desenvolvimento de fungos (O'BRIEN et alii, 1963). Esta desvantagem foi superada pela lavagem com água clorada, reduzindo o número inicial de bactérias em aproximadamente $90 \%$ e retardando marcadamente o crescimento subsequente de am bos, bactérias e fungos (MERCER et alii, 1961; O'BRIEN et alii, 1963). 


\section{MATERIAL E METODOS}

3.7. Material

O material utilizado na anälise constituiu-se de amostras de tomate provenientes de värias regiões tomateiras do Estado de são Paulo, coletadas antes e apōs a lavagem na linha de processamento, amostras de suco pré-aquecido antes da concentração e de polpas e extratos coletados semanal mente em uma indüstria alimentícia no município de Botucatu.

3.2. Meios de curtura

os meios de cultura utilizados foram os seguin tes:

a. Paza contagem total de mierorganismos: Glicose Triptona Ex trato de Levedura (GTY). 
- Triptona

- Glicose

- Extrato de levedura

- Agar

- Agua destilada
$5,0 \mathrm{~g}$ $.5,0 \mathrm{~g}$ $3,0 \mathrm{~g}$ $15,0 \mathrm{~g}$ $1000 \mathrm{ml}$

O pH foi ajustado a 7,0 e o meio esterilizado

a $121^{\circ} \mathrm{C}$ por 15 minutos.

b. Para contagem de Bacillus coagulans: NCA-ägar

- Triptona

- Glicose

- Agar

- Pürpura de Bromocresol 0,4\% $10,0 \mathrm{~g}$

- Agua destilada

o pH foi ajustado a 6,7 e o meio esterilizado

a $121^{\circ} \mathrm{C}$ por 15 minutos.

\subsection{Métodos}

\subsubsection{Coleta das amostras}

Visando a obtenção de dados mais representativos, a amostragem dos diferentes produtos analisados foi efe- 
tuada semanalmente.

O transporte da lavoura para a iñústria é fe to por caminhões, sendo o tomate acondicionado em caixas de material plảstico.

As amostras de tomate bruto foram coletadas, ao acaso, dos caminhões na indústria e colocadas em sacos plásticos para posterior análise microbiológica em laboratório.

As amostras de tomate lavado foram coletadas, ao acaso, da esteira de rolos giratōrios, onde as impurezas aderidas aos frutos são retiradas atravês de aspersores de ägua, e colocadas em sacos plästicos da mesma forma que as amostras de tomate bruto.

As amostras de suco, polpa ou extrato foram co letadas na indủstria em frascos Erlenmeyers esterilizados e tamponados com algodão.

As amostras de suco foram coletadas apôs as ex tratoras-refinadoras, onde o suco, após o tomate ter sido que brado e pré-aquecido, é obtido pela trituração do tomate que brado, extração e refinạ̃ão do suco.

As amostras de polpa foram coletadas à saida dos concentradores, de onde a polpa sai com cerca de $22^{\circ}$ Brix. Apôs a concentração, a polpa pode ser embalada 
e armazenada, ou então, diretamente transformada em produtos como extratos de diferentes concentraçöes e catchup.

As amostras de extrato foram coletadas após a adição e homogeneização dos ingredientes (sal - 1-3요), porém, antes do seu enlatamento.

\subsubsection{Preparo das amostras}

A anảlise microbiolōgica das amostras de tomate bruto e lavado foi feita utilizandorse almofariz com pisti lo esterilizados, onde $10 \mathrm{~g}$ de diferentes frutos de cada cole ta foram macerados sem adição de água. A seguir, adicionava-se $90 \mathrm{ml}$ de água destilada esterilizada ao macerado, obtendo -se a diluição $10^{-1}$. Em seguida, foi feita a diluição em série das amostras com água destilada esterilizada até $10^{-5}$, uti lizada para se fazer a contagem total de microrganismos em meio GTY. Para a contagem total de B, coagulans, em meio NCA, foi utilizada a diluição $10^{-4}$.

Para contagem total de esporos e contagem de esporos de Bacillus coagulans foi utilizada a diliuição $10^{-1}$ depois de ter sido submetida ao choque térmico, visando ativar a germinação dos esporos e destruir células vegetativas.

No caso das amostras de suco, polpa ou extrato de tomate, os frascos Erlenmeyers, contendo esses produtos, fo 
ram abertos em condições assëpticas, depois de homogeneizados. A seguir, foi feita a diluição em série dảs amostas com ăgua destillada esterilizada até $10^{-2}$, que foi a diluiçăo utiIizada para a contagem total de microrganismos em GTY. Para a contagem total de Bacillus coagulans, em meio NCA, foi utilizada a diluição $10^{-1}$.

Para a contagem total de esporos e contagem de esporos de Bacillus coagulans nestes produtos foi também utilizada a diluição $10^{-1}$, depois de ter sido submetida ao choque térmico.

3.3.3. Contagem de Bacillus coagulans em tomate e pro dutos derivados

Através da distribuição das diluições apropria das das anostras $\left(10^{-1}, 10^{-2}, 10^{-3}, 10^{-4}\right)$ em placas de Petri esterilizadas com meio NCA-ägar, indicado pela Nacional Canners'Association (1968), foi possível verificar a presença ou não de Bacillus coagulans, pois, quando este microrganismo está presente, ele germina e produz ācido, aparecendo na forma de colônias anarelas circulares e translücidas, produzindo $I$ halo amarelo sobre fundo roxo, apös incubação a $45^{\circ} \mathrm{C}$ por 48 horas. 
3.3.3.1. Contagem total

Foi feita a diluição em série das amostras $\left(10^{-1}, 10^{-2}, 10^{-3}, 10^{-4}\right)$ com água destilada esterilizada. A seguir, foi colocado, em duplicata, 1,0 ml da diluição apropriada com meio $\mathrm{NCA}$ liquefeito e resfriado a $45^{\circ} \mathrm{C}-50^{\circ} \mathrm{C}$ em placas de Petri, previamente marcadas. O meio foi homogeneizado com movimentos rotativos em forma de oito, para distribuir uniformemente os microrganismos e permitir o resfriamento e a disposição do mesmo.

As placas de Petri foram incubadas a $45^{\circ} \mathrm{C}$ por 48 horas.

As colōnias amarelas foram contadas e tidas co mo o nümero total de Bacillus coagulans por grama de material.

\section{$3,3,3,2$, Contagem de esporos}

Para a contagem de esporos, a diluição apropriada das amostras $\left(10^{-1}\right)$ foi aquecida a $85^{\circ} \mathrm{C}$ por 10 minutos em banho-maria. Logo apôs o aquecimento, as amostras foram retiradas do banho-maria e colocadas imediatamente em banho de gelo. Esse choque térmico visa ativar a germinação dos esporos e destruir cẻlulas vegetativas de microrganismos presentes. A seguir, 1,0 ml da diluição apropriada de cada 
amostra foi colocado, em duplicata, em placas de Petri com meio NCA liquefeito a $45^{\circ} \mathrm{C}-50^{\circ} \mathrm{C}$. O meio foi homogeneizado para distribuição uniforme dos microrganismos, com movimentos horizontais em forma de oito.

As placas foram incubadas a $45^{\circ} \mathrm{C}$ por 48 horas. As colonnicas amarelas foram contadas e tidas com o número de esporos de Bacillus coagulans por grama de material.

OBS.: As amostras, depois de diluỉas e colocadas, em duplica ta, em placas de Petri com o meio NCA para verificar a presença ou não de Bacillus coagulans, foram incubadas a $45^{\circ} \mathrm{C}$ durante 48 horas, e não a $37^{\circ} \mathrm{C}$ como proposto ini cialmente, pois, constatamos que essa temperatura parece ser adequada ao desenvolvimento de muitos microrga-. nismos, que poderiam inibir o crescimento da bactëria em questão, Como sabemos, Bacillus coagulans apresenta uma temperatura ötima de crescimento em torno de $45^{\circ} \mathrm{C}$, a qual não se mostra fávorável ao desenvolvimento de ou tros microrganismos. 
3.3.4, Contagem de microrganismos em tomate e seus produtos

\subsubsection{Contagem total}

Foi feita a diluição em sêrie das amostras $\left(10^{-1}, 10^{\mathrm{m}-2}, 10^{-3}, 10^{-4}, 10^{-5}\right)$ com ågua destilaảa esterilizada. A seguir, foi colocado 1,0 $\mathrm{ml}$ da diluição apropriada em placas de Petri, previamente marcadas, com meio GTY liquefeito e resfriado a $45^{\circ} \mathrm{C}-50^{\circ} \mathrm{C}$. O meio foi também homogeneizado com movimentos rotativos em forma de oito.

As placas foram incubadas a $37^{\circ} \mathrm{C}$ por 48 horas. Todas as colônias foram contadas.

\section{$3,3,4,2$ : Contagem de esporos}

Para a contagem de esporos, a diluição apropriada $\left(10^{-1}\right)$ das amostras foi aquecida a $85^{\circ} \mathrm{C}$ por 10 minutos em banho-maria, Logo apôs o aquecimento, as amostras foram colocadas imediatamente em banho de gelo. A seguir, 1,0 ml da diluição apropriada de cada amostra foi colocàdo, em du plicata, em placas de Petri com meio GTY liquefeito a $45^{\circ} \mathrm{C}$ - $50^{\circ} \mathrm{C}$. O meio foi homogeneizado para distribuição uniforme dos microrganismos, com movimentos horizontais em forma de oi to. 
.27 .

As placas foram incubadas a $37^{\circ} \mathrm{C}$ por 48 horas. Todas as colônias foram contadas. 


\section{RESULTADOS E DISCUSSÃO}

As análises microbiológicas realizadas em amos tras de tomate e seus derivados indicam que embora esses produtos sejam ácidos, estão sujeitos à deterioração, pois, apre. sentam uma flora microbiana variảvel.

Os resultados referentes às contagens totais de microrganismos e de Bacillus coagulans encontram-se nas Ta belas 1 a 8 . Os dados representam o nủmero de microrganismos (média de duas placas) por grama da amostra. Os resultados da análise estatística constam da Tabela 9.

Pelos resultados podemos verificar que as amos tras de tomate bruto apresentaram uma elevada contaminação to tal de microrganismos (um mínimo de $4,50 \times 10^{5}$ e um máximo de $114,00 \times 10^{5}$ ) por grama da amostra, enquanto as amostras de tomate lavado apresentaram maior contaminação total de es- 
poros (de $7,50 \times 10^{1}$ a $831,00 \times 10^{1}$ ) por grama da amostra.

Quanto à incidência de Bacillus cóagulans, verificamos que as amostras de tomate bruto mostraram maior ten dência à contaminação com esta bactéria, tanto em contagem to tal (de 0,00 a $14,50 \times 10^{4}$ ) como em contagem de esporos (de 0,00 a $30,50 \times 10^{1}$ ) por grama ca amostra, o que seria de se esperar. Nenhuma amostra de polpa apresentou ocorrência de Bacillus coagulans na contagem total, porém, algumas mostraram ocorrência de esporos (duas amostras; 1,00 e 1,50 x $10^{1}$ por grama da amostra). Por outro lado, as amostras de suco de tomate, que sofreram um pré-aquecimento, não apresentaram esporos, mas, pequena incidência de contaminação total de Bacillus coagulans (três amostras: $1,00,1,50$ e 6,00 x 10 ${ }^{1}$ ) por mI da amostra.

os dados estatisticos mostram diferença significativa a nivel de $1 \%$ de probabilidade entre as diversas eta pas de processamento para a contagem total de microrganismos, mas, não indicam variação entre as procedências das amostras. Para a contagem total de esporos não constatamos diferença significativa tanto entre etapas como entre procedências.

Na contagem total de Bacillus coagulans, os da dos mostram que houve diferença ao nivel de $1 \%$ de significância entre as etapas e de $5 \%$ entre as procedências, enquanto para a contagem de esporos desta bactëria, constatamos dife-. rença significativa a nivel de $5 \%$ entre as etapas de processa 
mento e de 1 z entre as procedências das amostras.

De um modo geral, o nümero de microrganismos presentes nas amostras analisadas foi grande, inclusive em su co, polpa e extrato de tomate, indicando má qualidade da maté ria-prima.

A incidência de Bacillus coagulans é baixa e de maneira a não preocupar, desde que $\circ \mathrm{pH}$ dos produtos seja mantido abaixo de 4,3 , de preferência abaixo de 4,2, quando a bactéria em questão terä poucas chances de se multiplicar e causar deterioração em produtos de tomate.

Devido a grande variação na incidência de $B a-$ cillus coagulans e de microrganismos em geral, torna-se dificil concluir qual a região que apresentou maior ou menor contaminação, pois, muitos fatores podem ter influenciado, como por exemplo, condição física do fruto durante a colheita e transporte, quantidade e tipo de solo aderente ao mesmo e seu tempo de armazenamento.

No que concerne à intensidade de contaminação das amostras de tomate analisadas, verificamos que a contagem total de esporos foi mais elevada que a contagem de esporos de Bacillus coagulans. Isso era de se esperar, uma vez que a ocorrência de termófilos no ambiente é muito mais restrita que a de mesófilos. Além disso, a metodologia analítica empregada foi bastante seletiva e diferencial no caso de Bacil- 
lus coagulans, o que não ocorreu para os outros tipos de microrganismos encontrados.

No que diz respeito à contaminação de produtos de tomate, a contagem total e de esporos foi mais reduzida, comparativamente à registrada nas matërias-primas, o que tambëm sexia de se esperar, uma vez que esses produtos jä foram submetidos à seleção e lavagem, além de uma sanificação ao longo do processamento.

O transporte do tomate da lavoura para a indús tria é efetuado, muitas vezes, em condições inadequadas, não oferecendo muita proteção ao fruto quanto à poeira e ao calor, especialmente se o local de produção é muito distante da indüstria.

Geralmente, o tomate fica sujeito às altas tem peraturas reinantes (conforme a época do ano), acelerando seu metabolismo e com isso provociando uma diminuição na consistên cia do fruto. Além disso, o calor propicia ao desenvolvimento de microrganismos.

O acondicionamento do tomate em caixas de mate rial plästico, em quantidades que excedem a capacidade das mesmas, faz com que haja compressão dos frutos, rompendo-se muitos deles. Este rompimento provoca não só o escoamento de suco, como também, fermentação parcial do mesmo. Além disso, o contacto de frutos sadios com outros danificados propicia 
uma maior contaminação fúngica e bacteriana da matéria-prima e das caixas.

Essas considerações deixam evidente a importân cia das operações de seleção e lavagem da matéria-prima por ocasião da recepção na unidade de processamento, no sentido de se eliminar frutos danificados ou em processo de decomposi ção, bem como, assegurar a remoção de terra e resíduos aderen tes. 
TABELA 1. Contagem de microrganismos (contagem total e contagem de esporos) em tomate bruto, sem lavar por grama de material.

\begin{tabular}{|c|c|c|c|}
\hline $\begin{array}{l}\text { Amos } \\
\text { tra }\end{array}$ & procedência & $\operatorname{CT}\left(x 10^{5}\right)$ & $\operatorname{CE}\left(\mathrm{x} 10^{1}\right)$ \\
\hline 1 & Bauru & 47,45 & 163,00 \\
\hline 2 & Bauru & 46,90 & incontável* \\
\hline 3 & Gaóriel Monteiro & 74,90 & incontável* \\
\hline 4 & Gabriel Monteiro & 63,95 & incontável* \\
\hline 5 & São Manoel & 29,75 & 70,50 \\
\hline 6 & Bauru & 45,40 & 57,00 \\
\hline 7 & São Manoel & 40,25 & 43,50 \\
\hline 8 & São Manoel & 21,90 & 34,50 \\
\hline 9 & São Manoel & 20,65 & 13,50 \\
\hline 10 & Cerqueira cẻsar & 28,00 & 18,00 \\
\hline 11 & Cerqueira César & 26,15 & 19,00 \\
\hline 12 & Bauru & 43,50 & 61,00 \\
\hline 13 & Gabriel Monteiro & 78,95 & incontável* \\
\hline 14 & São Manoel & 31,25 & 59,50 \\
\hline 15 & São Manoel & 29,50 & 32,00 \\
\hline 16 & Itatinga & 11,25 & 22,00 \\
\hline 17 & Birigui & 7,95 & 49,00 \\
\hline 18 & Presidente Prudente & 57,25 & 39,50 \\
\hline 19 & Birigui & 24,70 & 45,00 \\
\hline 20 & Clementina & 59,80 & 52,00 \\
\hline 21 & Coroados & 4,50 & 21,00 \\
\hline 22 & Birigui & 17,90 & 87,00 \\
\hline 23 & Narandiba & 101,50 & 74,50 \\
\hline 24 & Coroados & 39,25 & 32,00 \\
\hline 25 & Lucélia & 48,40 & 59,00 \\
\hline 26 & Narandiba & 14,00 & 17,50 \\
\hline 27 & Coroados & 114,00 & 23,00 \\
\hline 28 & Salmourão & 90,00 & 26,00 \\
\hline 29 & Birigui & 18,30 & 70,00 \\
\hline 30 & Coroados & 21,70 & 24,00 \\
\hline U & & $41,96 \times 10^{5}$ & $40,43 \times 10 !$ \\
\hline
\end{tabular}

* presença de uma colonia granảe invadindo toda a placa. 
TABELA 2. Contagem de Bacillus coagulans (contagem total e contagem de esporos) em tomate bruto por grama da amostra.

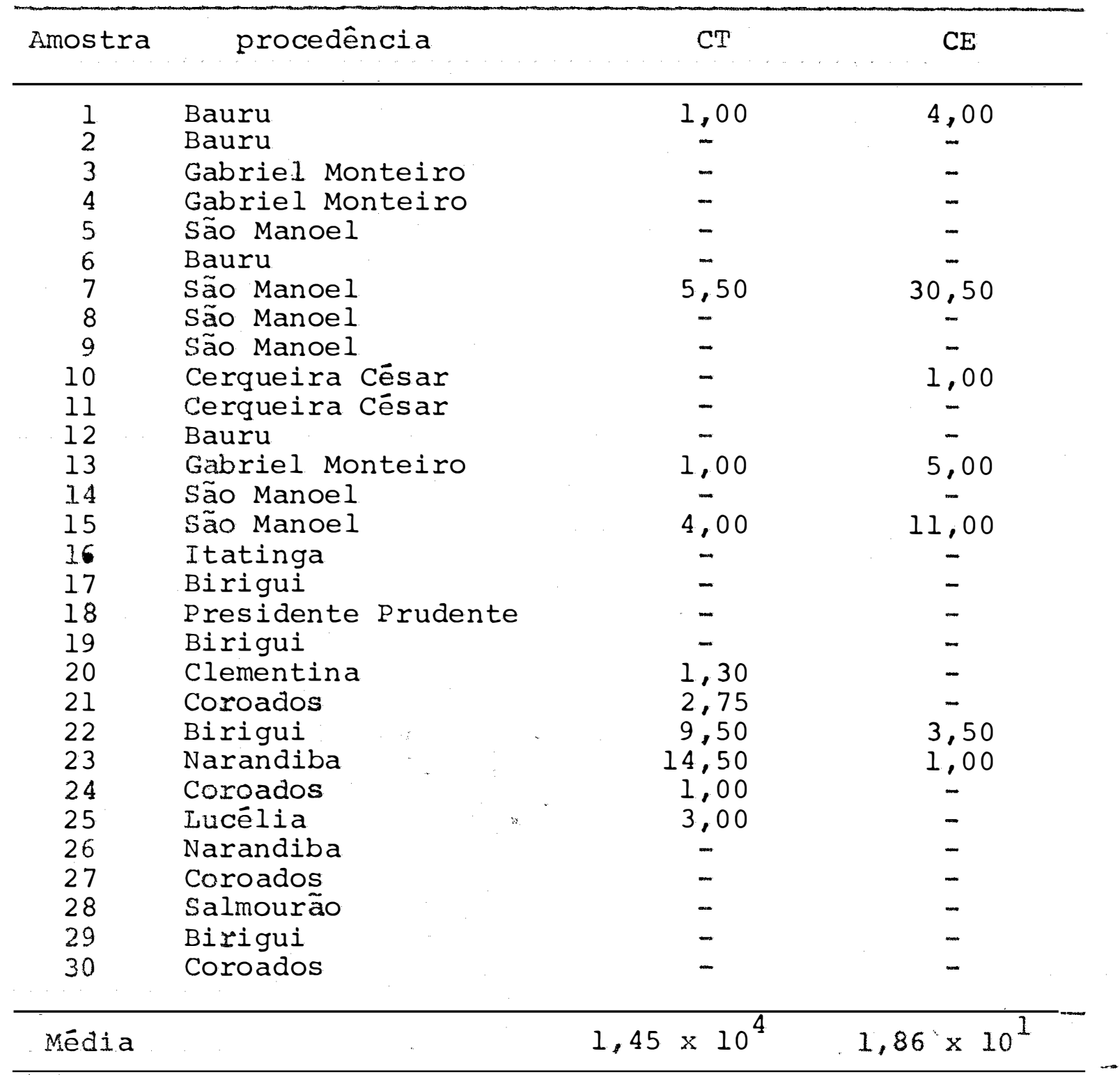

- ausência de Bacillus coagulans. 
TABELA 3. Contagem de microrganismos (contagem total e contagem de esporos) em tomate lavado por grama da amos-. tra.

\begin{tabular}{cl} 
Amostra & \multicolumn{1}{c}{ procedência } \\
\hline 1 & Bauru \\
2 & Bauru \\
3 & Gabriel Monteiro \\
4 & Gabriel Monteiro \\
5 & São Manoel \\
6 & Bauru \\
7 & São Manoel \\
8 & São Manoel \\
9 & São Manoel \\
10 & Cerqueira César \\
11 & Cerqueira Cêsar \\
12 & Bauru \\
13 & Gabriel Monteiro \\
14 & São Manoel \\
15 & São Manoel \\
16 & Itatinga \\
17 & Birigui \\
18 & Presidente Prudente \\
19 & Birigui \\
20 & Clementina \\
21 & Coroados \\
22 & Birigui \\
23 & Narandiba \\
24 & Coroados \\
25 & Lucélia \\
26 & Narandiba \\
27 & Coroados \\
28 & Salmourão \\
29 & Birigui \\
30 & Coroados \\
&
\end{tabular}

$\operatorname{ct}\left(x 10^{5}\right)$

CE $\left(x 10^{1}\right)$

Bauru

Bauru

Gabriel Monteiro

Gabriel Monteiro

São Manoel

São Manoel

São Manoel

Cerqueira cësar

Bauru

Gabriel Monteixo

São Manoel

São Manoel

Itatinga

Birigui

Presidente Prudente

Birigui

Clementina

Coroados

Birigui

Narandiba

Coroados

Iucélia

Narandiba

Birigui

Coroados
33,65

38,15

66,40

50,25

12,55

30,65

29,00

18,60

17,50

10,05

9,70

37,90

68,40

22,30

19,90

9,80

3,70

38,90

8,40

36,55

2,05

12,40

90,00

20,65

25,85

9,15

99,00

59,00

8,70

11,40
61,00

831,00

538,50

incontāvel *

30,00

40,00

38,00

25,00

7,50

15,50

17,00

49,00

25,00

40,00

17,00

12,00

19,50

37,00

26,50

48,50

10,00

27,00

67,00

29,50

47,00

7,50

11,00

21,00

11,00

11,00

Média

$30,01 \times 10^{5}$

$70,65 \times 10^{\overparen{1}}$

* presença de uma colonia grande invadindo toda a placa. 
TABELA 4. Contagem de Bacillus coagulans (contagem total e contagem de esporos) em tomate lavado por grama da amostra.

\begin{tabular}{|c|c|c|c|}
\hline Amostra & procedência & CT & $\mathrm{CE}$ \\
\hline 1 & Bauru & 1,00 & - \\
\hline 2 & Bauru & - & - \\
\hline 3 & Gabriel Monteiro & - & 6,50 \\
\hline 4 & Gabriel Monteiro & - & - \\
\hline 5 & São Manoel & - & - \\
\hline 6 & Bauru & - & - \\
\hline 7 & São Manoel & 4,00 & 23,00 \\
\hline 8 & São Manoel & - & - \\
\hline 9 & São Manoel & - & - \\
\hline 10 & Cerqueira César & - & - \\
\hline 11 & Cerqueira César & - & - \\
\hline 12 & Bauru & - & - \\
\hline 13 & Gabriel Monteiro & 1,00 & 3,50 \\
\hline 14 & São Manoel & - & - \\
\hline 15 & São Manoel & 2,00 & 5,50 \\
\hline 16 & Itatinga & - & 1,00 \\
\hline 17 & Birigui & - & -0 \\
\hline 18 & Presidente Prudente & - & - \\
\hline 19 & Birigui & - & - \\
\hline 20 & Clementina & 4,00 & 1,00 \\
\hline 21 & Coroados & - & - \\
\hline 22 & Birigui & - & - \\
\hline 23 & Narandiba & 9,00 & - \\
\hline 24 & Coroados & 1,50 & - \\
\hline 25 & Lucélia & 2,00 & - \\
\hline 26 & Narandiba & 13,00 & - \\
\hline 27 & Coroados & - & - \\
\hline 28 & Salmourão & - & - \\
\hline 29 & Birigui & - & - \\
\hline 30 & Coroados & - & - \\
\hline dia & & $1,25 \times 10^{4}$ & $1,35 \times 10^{1}$ \\
\hline
\end{tabular}


TABELA 5. Contagem de microrganismos (contagem total e contagem de esporos) em suco de tomate pré-aquecido por ml da amostra.

\begin{tabular}{|c|c|c|c|}
\hline Amostra & procedência & $\mathrm{CT}\left(\mathrm{x} 10^{2}\right)$ & $\mathrm{CE}\left(\mathrm{x} 10^{1}\right)$ \\
\hline $\begin{array}{l}1 \\
2 \\
3 \\
4 \\
5 \\
6 \\
7 \\
8 \\
9 \\
10 \\
11 \\
12 \\
13 \\
14 \\
15 \\
16 \\
17 \\
18 \\
19 \\
20 \\
21 \\
22 \\
23 \\
24 \\
25 \\
26 \\
27 \\
28 \\
29 \\
30\end{array}$ & $\begin{array}{l}\text { Bauru } \\
\text { Bauru } \\
\text { Gabriel Monteiro } \\
\text { Gabriel Monteiro } \\
\text { São Manoel } \\
\text { Bauru } \\
\text { São Manoel } \\
\text { São Manoel } \\
\text { São Manoel } \\
\text { Cerqueira Cēsar } \\
\text { Cerqueira César } \\
\text { Bauru } \\
\text { Gabriel Monteiro } \\
\text { São Manoel } \\
\text { São Manoel } \\
\text { Itatinga } \\
\text { Birigui } \\
\text { Presidente Prudente } \\
\text { Birigui } \\
\text { Clementina } \\
\text { Coroados } \\
\text { Birigui } \\
\text { Narandiba } \\
\text { Coroados } \\
\text { Lucēlia } \\
\text { Narandiba } \\
\text { Coroados } \\
\text { Salmouräo } \\
\text { Birigui } \\
\text { Coroados }\end{array}$ & $\begin{array}{r}14,25 \\
16,45 \\
2,90 \\
52,45 \\
8,00 \\
39,30 \\
1,90 \\
33,50 \\
7,65 \\
8,40 \\
7,80 \\
9,10 \\
24,40 \\
11,00 \\
8,90 \\
7,90 \\
11,10 \\
9,50 \\
9,00 \\
9,80 \\
12,15 \\
29,70 \\
34,10 \\
19,80 \\
19,00 \\
11,50 \\
7,70 \\
16,50 \\
9,90 \\
14,05\end{array}$ & $\begin{array}{c}24,00 \\
126,00 \\
2,00 \\
191,50 \\
20,00 \\
38,00 \\
\text { incontāvel* } \\
66,50 \\
33,50 \\
26,00 \\
14,50 \\
18,00 \\
34,50 \\
29,00 \\
14,00 \\
53,50 \\
51,50 \\
23,00 \\
15,00 \\
4,00 \\
69,00 \\
18,50 \\
19,00 \\
32,50 \\
30,00 \\
33,00 \\
27,00 \\
66,00 \\
20,50 \\
29,00\end{array}$ \\
\hline dia & & $15,59 \times 10^{2}$ & $37,3 \times 10^{1}$ \\
\hline
\end{tabular}

* presença de uma colonia grande invadindo toda a placa. 
TABELA 6. Contagem de Bacillus coagulans (contagem total e contagem de esporos) em suco de tomate pré-aquecido por ml da amostra.

\begin{tabular}{|c|c|c|c|}
\hline Amostra & Procedência & $\mathrm{Cr}$ & $C E$ \\
\hline 1 & Bauru & - & - \\
\hline 2 & Bauru & - & - \\
\hline 3 & Gabriel Monteiro & - & - \\
\hline 4 & Gabriel Monteiro & - & - \\
\hline 5 & são Maroel & - & - \\
\hline 6 & Bauru & - & - \\
\hline 7 & são Manoel & - & - \\
\hline 8 & são Manoel & - & - \\
\hline 9 & são Manoel & - & - \\
\hline 10 & Cerqueira César & - & - \\
\hline 11 & Cerqueira Cësar & - & - \\
\hline 12 & Bauru & - & - \\
\hline 13 & Gabriel Monteixo & - & - \\
\hline 34 & são Manoel & - & - \\
\hline 15 & são Manoel & - & - \\
\hline 16 & Itatinga & - & - \\
\hline 17 & Biriģui & - & - \\
\hline 18 & Presidente Pruderte & - & - \\
\hline 19 & Birigui & 1,0 & - \\
\hline 20 & Clementina & - & - \\
\hline 21 & Coroados & 1,50 & - \\
\hline 22 & Birigui & 6,00 & - \\
\hline 23 & Narandiba & - & - \\
\hline 24 & Coroados & - & - \\
\hline 25 & Lucélia & - & - \\
\hline 26 & Narandiba & - & - \\
\hline 27 & Coroados & - & - \\
\hline 28 & Salmourão & - & - \\
\hline 29 & Birigui & $-m$ & - \\
\hline 30 & Coroados & - & - \\
\hline Média & & $0,28 \times 10^{1}$ & - \\
\hline
\end{tabular}


TABELA 7. Contagem de microrganismos (contagem total e contagem de esporos) em extrato ou polpa de tomate por grama da amostra.

\begin{tabular}{|c|c|c|c|}
\hline Amostra & procedência & $\operatorname{CT}\left(x 10^{2}\right)$ & $C E\left(x 10^{1}\right)$ \\
\hline 1 & Bauru & 2,45 & 2,50 \\
\hline 2 & Bauru & 57,20 & 151,50 \\
\hline 3 & Gabriel Monteiro & 52,65 & 140,00 \\
\hline 4 & Gabriel Monteiro & incontävel * & incontāvel* \\
\hline 5 & São Manoel & incontävel * & incontāvel * \\
\hline 6 & Bauru & 46,25 & 27,50 \\
\hline 7 & São Manoel & 1,60 & 5,50 \\
\hline 8 & São Manoel & 16,75 & 24,00 \\
\hline 9 & São Manoel & 7,70 & 9,00 \\
\hline 10 & Cerqueira César & 30,75 & 180,50 \\
\hline 11 & Cerqueira César & 28,90 & 59,50 \\
\hline 12 & Bauru & 38,50 & 55,00 \\
\hline 13 & Gabriel Monteiro & 58,20 & incontāvel * \\
\hline .14 & São Manoel & 10,20 & 22,50 \\
\hline 15 & São Manoel & 9,50 & 15,00 \\
\hline 16 & Itatinga & $6,7 C$ & 35,00 \\
\hline 17 & Birigui & 20,70 & 69,00 \\
\hline 18 & Presidente Prudente & 24,80 & 19,50 \\
\hline 19 & Birigui & 15,60 & 49,50 \\
\hline 20 & Clementina & 22,35 & 82,00 \\
\hline 21 & Coroados & 18,10 & 45,00 \\
\hline 22 & Birigui & 38,25 & 34,50 \\
\hline 23 & Narandiba & 2,75 & 55,00 \\
\hline 24 & Coroados & 18,40 & 60,00 \\
\hline 25 & Lucélia & 19,70 & 90,00 \\
\hline 26 & Narandiba & 10,25 & 60,00 \\
\hline 27 & Coroados & 14,80 & 38,00 \\
\hline 28 & Salmourão & 38,00 & 55,00 \\
\hline 29 & Birigui & 19,90 & 56,00 \\
\hline 30 & Coroados & 15,90 & 39,50 \\
\hline Mēdi & & $21,56 \times 10^{2}$ & $49,35 \times 10^{1}$ \\
\hline
\end{tabular}

* presença de uma colonia grande invadindo a placa. 
.40 .

TABELA 8. Contagem de Bacillus coagulans (contagem total e contagem de esporos) em extrato ou polpa de tomate por grama da amostra.

\begin{tabular}{|c|c|c|c|}
\hline Amostra & procedência & $\mathrm{CT}$ & $\mathrm{CE}$ \\
\hline 1 & Bauru & - & - \\
\hline 2 & Bauru & - & - \\
\hline 3 & Gabriel Monteiro & - & - \\
\hline 4 & Gabriel Monteiro & - & - \\
\hline 5 & São Manoel & - & - \\
\hline 6 & Bauru & - & - \\
\hline 7 & são Manoel & - & \\
\hline 8 & são Manoel & - & - \\
\hline 9 & são Manoel & - & - \\
\hline 10 & Cerqueira César & - & - \\
\hline 21 & Cerqueira César & - & - \\
\hline 12 & Bauru & - & - \\
\hline 13 & Gabriel Monteiro & - & - \\
\hline 14 & São Manoel & - & - \\
\hline 15 & são Manoel & - & - \\
\hline 16 & Itatinga & - & - \\
\hline 17 & Birigui & - & - \\
\hline 18 & Presidente Prudnete & - & - \\
\hline 19 & Birigui & - & - \\
\hline 20 & Clementina & - & 1,00 \\
\hline 21 & Coroados & - & 1,50 \\
\hline 22 & Birigui & - & - \\
\hline 23 & Narandiba & - & - \\
\hline 24 & Coroados & - & - \\
\hline 25 & Lucélia & - & - \\
\hline 26 & Narandiba & - & - \\
\hline 27 & Coroados & - & - \\
\hline 28 & salmourão & - & - \\
\hline 29 & Birigui & - & - \\
\hline 30 & Coroados & - & - \\
\hline dia & & - & $0.08 \times 10^{1}$ \\
\hline
\end{tabular}


.41.

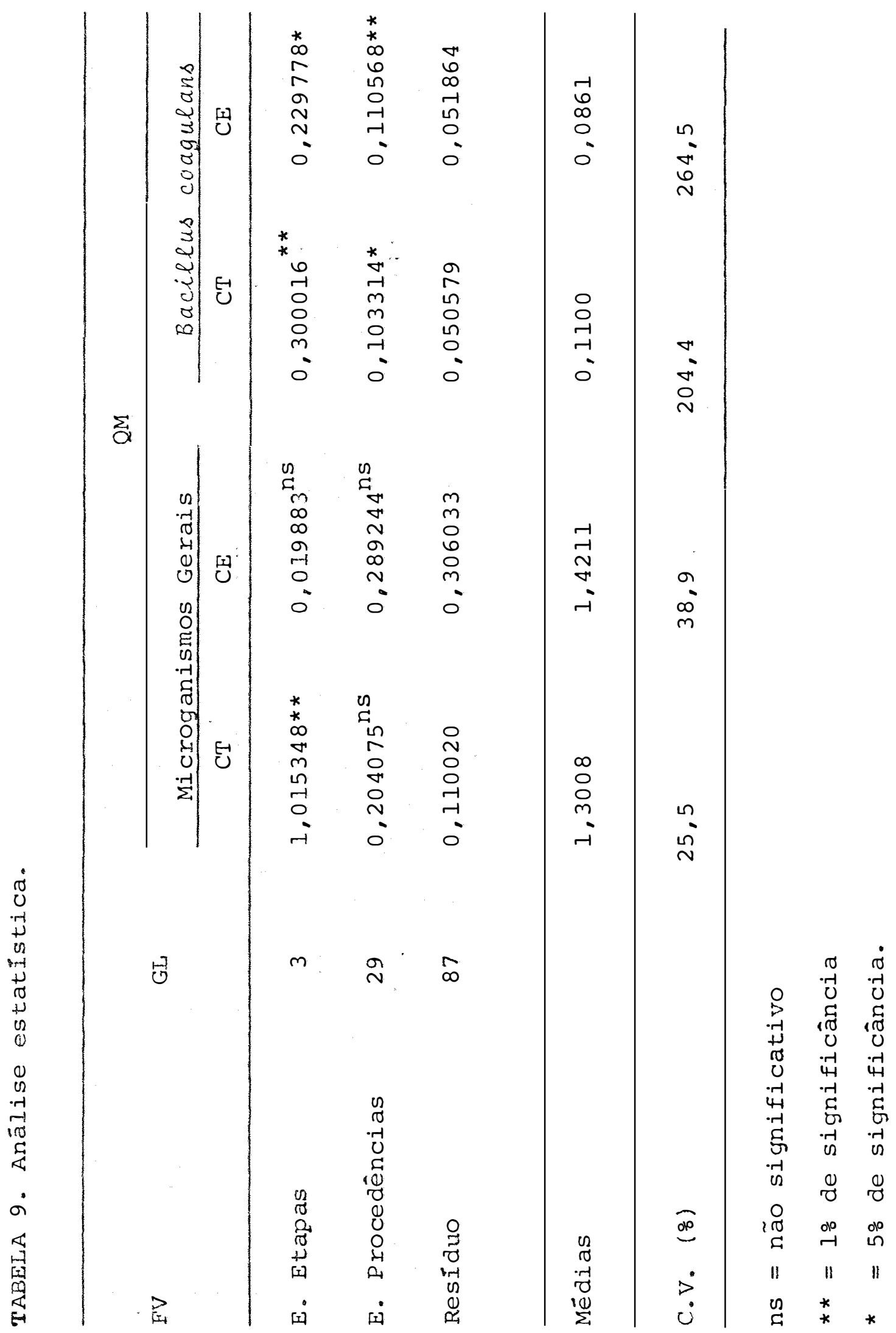


5. CONCLUSÕES

a. As amostras de tomate e seus produtos apresentaram uma carga microbiana variảvel.

b. De um modo geral, o nümero de microrganismos presente nas amostras das vảrias fases da industrialização foi grande.

c. Houve uma sensivel variação nos niveis de contaminação nos diferentes produtos examinados.

d. Não se pôde concluir qual a região tomateira que apresentou maior ou menor contaminação.

e. A incidência de Bacillus coagulans foi considerada ser baixa no Estado de são Paulo.

f. Entre as amostras analisadas, as de tomate bruto apresentaram maior incidència de Bacillus coagulans, 
.43.

tanto em contagem total como em contagem de esporos, além de maior contaminação total de microrganismos.

9. A contagem total e contagem de esporos totais em tomates foi maior que nos produtos de tomate.

h. A contagem total de esporos foi maior que a contagem de esporos de Bacillus coagulans nas amostras analisadas. 


\section{LITERATURA CITADA}

ANUARIO ESTATISTICO DO BRASIL, 1982. Secretaria de planejamento da Presidência da Repủblica. Fundação Instituto Bra sileiro de Geografia e EStatistica ". IBGE.

BECKER, M.E, e C.S. PEDERSON, 1950. The physiological characters of Bacillus coagulans (Bacillus thenmoaciduransl. J. Bacteriol:. 59(6): 717.

BERRY, $R_{*} N_{0}, 1933$. Some new heat resistant, acid tolerant organisms causing spoilage in tomato juice. J. Bacteriol $25: 720.73$

BREED, R.S., P.S. PRICKETI, M.W. YALE, 1929. The significance of thermophilic spore-forming bacteria in pasteurized milk. J. Bacteriol. 17: $37-38$. 
CAMERON, E.J. e W.D. BIGELOW, 1931. Elimination of thermophilic bacteria from sugar. Ind. Eng. Chem. 23: 1330$-1333$.

CANNED FOOD REFERENCE MANUAL, 1949. Third Edition. American Can Co. 524.

CLARK, F.M. e F.W. TANNER, 1937. Thermophilic canned-food spoilage organisms in sugar and starch. Food Res. 2:27-39.

CORDES, W.A., 1928. Bacterial action in the coagulation of evaporated milk. J. Dairy Sci., 11: 46-.51.

DEFIGUEIREDO, P.M. e F.D. SPLITTSTOESSER, 1976. Food Microbiology. The Avi Publishing Company, INC. Westport, Connecticut.

DESROSIER, N.W. e F. HEIIIGMAN, 1956. Heat activation of bac terial spores. Food Res. 21: 54-62.

DOYLE, E.S., W.A. MERCER, J.N. DEMSEY, C.W. BOHRER e J. YESSAIR, 1958. Sanitation of canning equipment. Natl. Canners' Assoc. Infoxin. Lettex, 56-61.

FIELDS, M.L., 1968. Thermophilic aerobic spore-forming bacteria in Hawaiian soils. Unpublished data, University of Missouri, Columbia, Missouri.

FIELDS, M.L., 1970. The flat sour bacteria. In: Advances in Food Research, 18, Academic Press, New York, 322 p. 
GORDON, R.E. e R.N. SMITH, 1949. Aerobic spore forming bacteria capable of growth at high temperatures. J. Bacteriol. 58: $327-341$.

HAMMER, B.W., 1915. Bacteriological studies on the coagulation of evaporated milk. Iowa. State Coll. Agr. Expt. Sta., Res. Bull. 19.

HANSEN, P.A., 1932. The public significance of the growth of termophilic bacteria in pasteurized milk. N.Y. State Agr. Expt. Sta. (Geneva, N.Y.), Tech. Bull. 196.

HUSSEIN, M.F.; H.A. KHALAF; EL SAMKARY e H. EL. MANSY, 1979. Studies on bacterial - Bacillus species - contamination of Egyptian tomato processing as canned tomatoes concentrate, sterilized and half sterilized (En). Cairo (Egypt). 14 p. Research Bulletin, Faculty of Agricultural no 1138.

HUSSONG, R.V. e B.W. HAMMER, 1928. A the rmophile coagulating milk under pratical conditions. J. Bacteriol. 15: 179$-188$.

INGERSOLI, C.D., 1930. Thermophiles in sugar. Food Ind., 2: 325 .

JENKINS, J.A., 1948. The origen of the cultivated tomato. Economic Botany, 2: 379-392. 
JONES, A:H. e E.W. FERGUSON, 1961. Factors affecting the development of acillus coagulans in fresh tomatoes and in canned tomato juice. Food Technol. 15: 107-110.

MARSH, C.L. e D.H. LARSEN, 1953. Characteriation of some thermophilic bacteria from the hot springs of Yellowstone National Park. J, Bacteriol. 65: 193-197.

MERCER, W.A., W. ROSE e J. CHAPPMAN, 1961. Comparative spore and breakage data fox mechanically harvested tomatoes. N.C.A. Progress Report.

MINAMI, K., 1980. The history of tomato production for industry in South America, Acta Horticultura, 100: 87--92.

NATIONAL CANNERS' ASSOCIATION, 1968. "Sanitation for the Food Preservation Industries". MC Grawnill, New York. O'BRTEN, M., G,K, YORK e S.L, LEONARD, 1963, Effect of bulk handling on canning tomatoes, Food Techmol. 17; 1050. PEDERSON, C.S. e M.E. BECKER, 194., Flat sour spoilage of tomato juice, N.Y. State Agr. Expt, Sta, (Geneva, N.Y.), Tech. Bull, 287.

RICE, A.C, e C.S. PEDERSON, 1954, Factors influencing growth of Bacillus coagulans in canmed tomato juice. Food Res. 19: $124-133$ 
RICHMOND, B. e M.I. FIELDS, 1966. Distribution of thermophiIic aerobic spore-forming bacteria in food ingredients. Appl. Microbiol. 14: 623-626.

RICK, C.M., 1967, Fruit and pedicel characteristics derived from Galapagos tomato. Economic Botany, 21: 171-184.

SMITH, N.R., R.E. GORDON e F.E. CLARK, 1952. Aerobic spore forming bacteria. U.S, Dept. Agr., Agr. Menograph no 16.

SOGNEFEST, P, e M.J. JACKSON, 1947, Presterilization of canned tomato juice, Food riechnol, 1: 78-84.

SPECK, U.R,, 1976. Aciduric Flat Sour Sporeformers. Compendium of Methods for the Microbiological Examinations of Foods, $248-253$.

STERN, R,M。, C,P, HEGARTY e O.B. WILLIAMS, 1942. Detection of Bacillus thermoacidurans (Berry) in tomato juice and successful cultivation of the organism in the laboratory. F'ood Res, , 7: 186-191,

TANNER, F.W., 1950. Laboratory Manual and Work Book in Microbiology of Foods. The Garrard Press, Champaign, Illinois.

TESSARIOLI NETO, J., 1980, Assistência Têcnica, Plano Nacio nal do Tomate. Seminấrio realizado em Presidente Prudente, 18 a 19 de setembro de 1980. 
TROY, V.S. e A.M. SCHENCK, 1960. "Flat sour spoilage of tomato juice", Continental Can. Co., Chicago, Illinois.

YORK, G.K., S.I. LEONARD, J.H. MaC GILLIVRAY, M. O'BRIEN, D. TOMBROPOULOS e G. ROWE, 1962. Effect of mechanical harvesting and bulk handling on the quality of processing tomatoes. Univ. Calif, (Davis) Progress Report.

YORK, G.K., R.J. HEIL, L.G. MARSH, A. ANSAR, L.R, MERSON, T. WOLCOTT E S. LEONARD, 1974. Thermobacteriology of canned whole peeled tomatoes. J, Food, Sci., 40: 764-769. 